\title{
Ranganathan continua em cena
}

RANGANATHAN, S. R. Ascinco leis da Biblioteconomia. Brasília: Briquet de Lemos Livros, 2009. 336 p.

\section{Maria das Graças Targino}

Pós-doutorado pelo Instituto Interuniversitario de Iberoamérica da Universidad de Salamanca, Espanha. Professora do Departamento de Comunicação Social da Universidade Federal do Piauí.

E-mail: gracatargino@hotmail.com

Década de 60. Graduação em biblioteconomia, Universidade Federal de Pernambuco. Como muitos outros estudantes de graduação, à época, tive contato com as denominadas "Cinco leis da Biblioteconomia", estabelecidas em 1928, e publicadas, pela primeira vez, ainda em 1931, pelo indiano Shiyali Ramamrita Ranganathan, sob o título Five laws of Library Science. Nascido em Shiyali, no Estado de Madras (hoje, Tamil Nadu), em 1892, e falecido em 1972, em Bangalire, Ranganathan se imortalizou por sua dedicação à matemática (sua formação inicial) e à biblioteconomia, na condição de primeiro bibliotecário da Universidade de Madras, com formação complementar na GrãBretanha. Sua vasta produção intelectual inclui centenas de artigos sobre a história da matemática e mais de 50 livros, voltados, também, para a teoria da classificação bibliográfica, a exemplo de Elements of library classification (1945); Classification and international documentation (1948) e Classification and communication, de 1951. Sua dedicação justifica ser ele conhecido como o "Pai da Biblioteconomia" na Índia.

Transcorridos mais de 40 anos, agora, são meus alunos de graduação que conhecem e reconhecem a relevância dos cinco preceitos. Estes vencem o tempo. Persistem como essenciais até os dias de hoje para quem consegue visualizar, na biblioteconomia, chance inigualável de exercer a cidadania e lutar pelo acesso universal, oportunizando a todos informações compatíveis às suas demandas informacionais e, portanto, lhes favorecendo a chance de exercitar direitos e deveres. Porém, numa época em que as discussões em torno das tecnologias de informação e de comunicação (TIC) prevalecem em quaisquer eventos da área, com a inserção de tópicos - como arquitetura para sistemas de biblioteca digital, copy left, preservação digital, acesso aberto, repositórios digitais, webometria, formato RSS [Realy Simple Syndication] para disseminação de informações em revistas eletrônicas etc.etc. -, os mais desavisados podem, diante das leis de Ranganathan, "torcer o nariz" e disfarçar sorriso zombeteiro:

1. Os livros são para usar.

2. A cada leitor seu livro.

3. A cada livro seu leitor.

4. Poupe o tempo do leitor.

5. A biblioteca é um organismo em crescimento.

Ora, por detrás de aparente ingenuidade, os enunciados propagados por Ranganathan são, em sua essência, os precursores de quaisquer movimentos liderados por profissionais bibliotecários hoje ditos da linha de frente. Aliás, reitero que a extrema simplicidade faz a grandeza dos empresários bemsucedidos da contemporaneidade, à semelhança do norte-americano Steven Paul Jobs, cofundador das empresas de informática Apple Inc., da NeXT e do estúdio Pixar, e criador do revolucionário ipod, cujas declarações públicas estão sempre impregnadas da certeza de que "[...] menos é sempre mais", e, mais enfaticamente, "simplicidade equivale à inteligência e complexidade, à confusão mental."

E mais, à época, a tônica dos serviços de biblioteca é a preservação e não a utilização das coleções. É Ranganathan que, em 1931, conforme versão de seu livro, ora lançado em português, 2009, sob o título As cinco leis da biblioteconomia e responsabilidade editorial de Briquet de Lemos Livros, ao longo de suas 336 páginas traduzidas pelo professor da Universidade de Brasília Tarcisio Zandonade, chama a atenção de governantes, bibliotecários e população em geral para as potencialidades da biblioteca como instituição social. Biblioteca como órgão capaz de romper as muralhas da exclusão, deixando sua condição de “depósito morto de livros" (p. 23) para se transformar em centro de cultura, a exemplo do 


\section{RECENSÃO}

que a primeira lei (Os livros são para usar) argumenta diante de seus interlocutores Regra do menor espaço e Regra do menor custo, que custam a entender as reivindicações da Primeira lei, no sentido de tornar a biblioteca um lugar aprazível e aconchegante, alterando a forma de armazenar as coleções, a própria localização da biblioteca, seu horário de funcionamento, seu mobiliário e, como inevitável, o perfil do elemento humano responsável pelo encaminhamento dos serviços.

Isto porque, ao longo da obra em pauta, Ranganathan opta por interessante estratégia. No decorrer dos capítulos, sobretudo, no caso daqueles que tratam mais especificamente das leis, o autor recorre a diálogos fictícios entre os elementos que perfazem a infraestrutura das instituições. Também lança mão de exemplos diversificados bastante ilustrativos e da análise da realidade do Oriente e do Ocidente, com ênfase, respectivamente, na Índia, e nos Estados Unidos da América e na Grã-Bretanha.

Enquanto a primeira prescrição substitui o perverso conceito de que os livros existem para serem preservados por uma concepção de biblioteca viva e dinâmica, a segunda - A cada leitor seu livro - enfatiza a multiplicidade de usuários a que a instituição pode atingir. $\mathrm{O}$ autor percorre tempos históricos e lugares para, então, apregoar o princípio de oportunidades igualitárias em relação à informação, aos livros, ao ensino e ao lazer:

[O segundo princípio] não terá descanso enquanto não houver reunido todos - ricos e pobres, homens e mulheres, quem mora em terra firme e quem navega os mares, jovens e idosos, surdos e mudos, alfabetizados e analfabetos - a todos, de todos os cantos da Terra, até que os tenha conduzido para o templo do saber e até que lhes tenha garantido aquela salvação que emana do culto de Sarasvati, a deusa do saber (p. 92).

Isto é, 81 anos atrás, Ranganathan já lutava pelo sonho de bibliotecas ação-cultural. Atividades hoje enunciadas quase como novidade, tal como iniciativas extensionistas, ações de biblioterapia, leitura para analfabetos, e outras, são previstas e incentivadas por ele, numa longínqua Índia e num tempo já ido. Sob esta ótica, a segunda norma corresponde ao "sucesso arrasador de livros para todos, em sua desimpedida digvijaya ou expedição de conquistas do mundo" (p. 94), o que faz com que o indiano Shiyali R. Ranganathan vague ao redor dos diferentes continentes e nações díspares, como África do Sul, Hungria, México, Rússia, Suécia, avaliando os serviços de biblioteca (capítulo três) para, no momento seguinte, em longo capítulo de 50 páginas, estudar as implicações da abrangência do enunciado - A cada leitor seu livro - em termos de Estado, entidades de classe e cidadãos.

O terceiro princípio, apesar de se aproximar do primeiro, uma vez que sua ênfase é o livro de fato, complementa o segundo. Este busca encontrar para cada leitor o livro adequado. Agora, a proposta A cada livro seu leitor - pretende identificar um leitor adequado para cada livro, o que corresponde à adoção de medidas variadas em consonância com cada realidade. Em outras palavras, em 1931, Ranganathan já alerta para os benefícios do acesso livre às estantes, para as imensuráveis vantagens de publicizar os serviços mantidos e, principalmente, para a necessidade imperiosa de diversificar e sistematizar as estratégias de dinamização e de uso das coleções. Até porque, se as três primeiras leis insistem para que as informações circulem intensamente incorporando um número sempre mais amplo de indivíduos, no caso da quarta prescrição, a ênfase recai na relevância de economizar tempo e energia dos leitores: Poupe o tempo do leitor. Isto resume, de forma implícita, a premência de se investir na administração e na organização de bibliotecas, de tal forma que o indivíduo não se perca no emaranhado de informações distribuídas em suportes distintos.

É ainda Shiyali Ramamrita Ranganathan quem traz à tona a assertiva de que - A biblioteca é um organismo em crescimento. Este último preceito, como os demais, conserva alto nível de atualização e adequação à dita sociedade da informação ou sociedade do conhecimento ou sociedade da aprendizagem. Em pleno século XXI, em meio 


\section{RECENSÃO}

ao domínio de fluxo informacional contínuo e inesgotável, onde as TICs marcam presença ostensiva e irreversível, mais do que nunca, bibliotecas e bibliotecários precisam se mover em direção ao futuro. No entanto - e isto é interessante de se discutir -, se àquela época, Ranganathan visualiza a biblioteca como instituição eminentemente social, e, portanto, passível de transmutação e de assimilação de novos paradigmas, esta é a prova cabal de que o fator determinante das mudanças societais e institucionais não é necessariamente tão-somente o tempo histórico. Ora, se o pensador indiano vislumbra vida ativa para coleções e bibliotecas desde seu lendário Five laws of Library Science, ainda agora, século XXI, ano 2009, é possível encontrar bibliotecas de todos os níveis que se mantêm alheias às prescrições de Ranganathan: acervos distantes dos leitores; leitores diante de regulamentos proibitivos; administradores aficionados por inovações tecnológicas e indiferentes às demandas de seu público-alvo, e assim por diante.

Sob tal ótica, é sempre um risco refazer a história das bibliotecas a partir tão-somente da fase histórica em que estão inseridas. É a ação profissional e a vontade política que, sempre, determinam o desempenho das instituições. Não importa conceituação ou categorização, se inexiste predisposição dos profissionais e dos governantes em consolidar as bibliotecas como centros de aprendizagem. Insisto, pois, que a distinção dos paradigmas - biblioteca tradicional (primazia das grandes coleções); biblioteca ação cultural (primazia dos usuários); biblioteca virtual (primazia do fluxo informacional) - soa falsa e artificial, quando nos movemos por bibliotecas cujos livros são conservados em estantes a sete chaves. São bibliotecas de poderosas faculdades particulares de ensino superior, cujas portas estão cerradas à visitação do público ou cujo acesso somente é possível mediante autorização formal da administração superior da entidade. E estou falando somente em consulta ao acervo, deixando de lado qualquer perspectiva de serviços rotineiros, como empréstimo domiciliar, quando as proibições são mais rígidas.
Tudo isto faz de As cinco leis da biblioteconomia um livro pleno de inquietações atuais, como a riqueza contida no browsing, as mudanças sociais (e tecnológicas) ininterruptas, e, por fim, a relevância do "pessoal da biblioteca que, em última análise, constrói ou destrói a biblioteca" (p. 25) em contraposição à tendência de se alocarem nas bibliotecas os mais imprestáveis:

Numa escola [...] o mais forte e cruel dentre os funcionários foi incumbido de ser o anjo da guarda da biblioteca [...] Ele provou ser um guardião muito zeloso [...] Um aluno aplicado teve a coragem de abordá-lo para pedir um livro para uma "leitura extra" [...]

"Que é que você quer?”, trovejou [o funcionário], quase chamuscando o garoto com seus olhos vermelhos.

"O livro Peeps at many lands: Japan, senhor", gaguejou o menino.

"Quanto você tirou no último trimestre?"

"Qua... quarenta e dois de cinqüenta, senhor."

"Vá embora e consiga os oito pontos restantes antes de pensar em 'leitura extra', foi a enfática recomendação acompanhada do punho direito [do funcionário], que o pousou, com uma força de doer, na testa do garoto, trêmulo, que fugiu [...] para nunca, nunca mais voltar à biblioteca (p. 29-30).

Enfim, mesmo sem desprezar os novos rumos da biblioteconomia, irreversíveis e inevitáveis e, sem dúvida, vantajosos, é impossível negar a adequação das cinco leis de Ranganathan. De uma forma ou de outra, comprovam ser A SOCIEDADE a única meta que justifica a biblioteconomia como profissão.

Artigo submetido em 02/09/2009 e aceito em 20/09/2010.

\section{REFERÊNCIAS}

RENAULT, L. V. Paradigmas e modelos: proposta de análise epistemológica para a ciência da informação. Transinformação, Campinas, v. 17, n. 2, p. 53-60, maio/ago. 2007.

TARGINO, M. das G. A biblioteca do século XXI: novos paradigmas ou meras expectativas? Informação \& Sociedade: Estudos, João Pessoa, v. 20, n. 1, p. 155-168, jan./abr. 2010.

WEIL, M. M. TechnoStress: coping with technology@work @home@play. New York: John Wiley \& Sons, 1997.240 p.

Ci. Inf., Brasília, DF, v. 39 n. 1, p.122-124, jan./abr., 2010 